\title{
INFLUÊNCIA DO POTÁSSIO E DA CALAGEM NA COMPOSIÇÃO QUÍMICA, QUALIDADE FISIOLÓGICA E NA ATIVIDADE ENZIMÁTICA DE SEMENTES DE SOJA
}

\author{
Influence of potassium and liming on chemical composition, physiological \\ quality and enzyme activities of soybean seeds
}

\author{
Adriano Delly Veiga ${ }^{1}$, Édila Vilela de Resende Von Pinho ${ }^{2}$, André Delly Veiga ${ }^{3}$, \\ Pedro Henrique de Andrade Resende Pereira ${ }^{4}$, Kênia Carvalho de Oliveira ${ }^{4}$, Renzo Garcia Von Pinho ${ }^{2}$
}

\begin{abstract}
RESUMO
A composição química das sementes pode ser influenciada por fatores genéticos, ambientais e pela disponibilidade de nutrientes no solo durante a produção e, como consequência, terem o seu vigor afetado. O potássio pode influenciar a atividade de várias enzimas presentes nas plantas, necessárias em várias reações envolvidas na utilização de energia, síntese de amido, metabolismo do nitrogênio e respiração. Avaliou-se o efeito da adubação potássica e da calagem na composição química, qualidade fisiológica e na atividade de enzimas de sementes de soja. A pesquisa foi desenvolvida nos laboratórios de análises e biotecnologia de sementes do Departamento de Agricultura e no Laboratório de Produção Vegetal do Departamento de Ciências dos Alimentos da Universidade Federal de Lavras (UFLA). Em sementes de soja do cultivar Msoy 8001, produzidas sob 2 níveis de saturação por base (48\% e $85 \%)$ e quatro doses de $\mathrm{K}_{2} \mathrm{O}$ por hectare $(0,50,100$ e $200 \mathrm{~kg}$ ), foram avaliados teores de óleo e proteína, germinação, envelhecimento acelerado e atividade das enzimas envolvidas nos processos de germinação e deterioração de sementes. A adubação potássica não afeta a germinação e o vigor das sementes, enquanto a elevação da saturação por base, proporciona maior vigor de sementes de soja. Há aumento no teor de óleo e redução no teor de proteína em sementes de soja à medida que a dose de $\mathrm{K}_{2} \mathrm{O}$ é aumentada. Ocorre aumento de teor de proteínas em sementes de soja, produzidas sob maiores níveis de saturação por base. A atividade das enzimas piruvato quinase, esterase e álcool desidrogenase em sementes de soja é afetada pela concentração de potássio e saturação por base no solo.
\end{abstract}

Termos para indexação: Nutrientes; sementes, qualidade, composição química.

\begin{abstract}
The chemical composition of seeds can be influenced by genetical and environmental factors and by the availability of nutrients in the soil during production, which consequently affect their vigor. Potassium can influence the activity of several enzymes present in plants. These enzymes are necessary in a number of reactions involved in the utilization of energy, starch synthesis, nitrogen metabolism and respiration. The effects of potassium fertilization and liming on the chemical composition, physiological quality and enzymes activities of soybean seeds were evaluated. The research was developed in the Seed Analysis Laboratory of the Agriculture Department and in the Plant Production Laboratory in the Food Science Department of the Federal University of Lavras, Lavras (UFLA). In soybean seeds of cultivar Msoy 8001 produced under two levels of base saturation (48\% and 85\%) and four doses. ha ${ }^{-1}$ of $\mathrm{K}_{2} \mathrm{O}, 0,50,100$ and 200, oil and protein contents, seed germination, aging test and the activity of some enzymes involved in the seed germination and deterioration processes were evaluated. Seed germination and vigor are not influenced by fertilization with potassium. However, base saturation increases the vigor of soybean seeds. Highert doses of potassium increase oil content and reduce protein in soybean seeds. High base saturation level increases the protein content. The activities of the enzymes piruvate kinase, esterase and alcohol dehydrogenase are altered by the doses of potassium and levels of soil base saturation.
\end{abstract}

Index termes: Nutrients, seeds, quality, chemical composition.

(Recebido em 25 de setembro de 2009 e aprovado em 3 de março de 2010)

\section{INTRODUÇÃO}

A disponibilidade de nutrientes pode influenciar a composição química das sementes e, consequentemente, seu metabolismo e vigor. Dessa forma, o adequado fornecimento de nutrientes favorece o desenvolvimento das plantas, condicionando-as a produzirem metabólitos necessários ao desenvolvimento de seus frutos e sementes. Nas sementes, é necessário que o acúmulo de reservas seja feito adequadamente, uma vez que o desenvolvimento inicial das plântulas depende dessas substâncias.

\footnotetext{
1Universidade Federal de Lavras/UFLA - Cx. P. 3037 - 37200-000 - Lavras, MG - adrveiga@yahoo.com.br

2Universidade Federal de Lavras/UFLA - Departamento de Agricultura/DAG -Lavras, MG

${ }^{3}$ Escola Agrotécnica Federal de Machado - Machado, MG

${ }^{4}$ Universidade Federal de Lavras/UFLA - Lavras, MG
} 
A composição química pode ser influenciada por fatores genéticos e ambientais e ainda pelos nutrientes aplicados no solo (Brim, 1973; Sediyama et al., 1981). Mascarenhas et al. (1991) e Tanaka et al. (1991) relataram a ocorrência de variações nos teores de óleo e de proteína em sementes de soja resultante do manejo da adubação ou da correção da acidez do solo. Como consequência, as enzimas atuantes em diferentes processos do metabolismo da planta são influenciadas pela composição química e podem atuar de forma diferenciada.

Está estabelecido que o $\mathrm{K}^{+}$é requerido para a síntese protéica em plantas. Plantas deficientes em K apresentam menor síntese de proteínas e acúmulos de compostos nitrogenados solúveis como aminoácidos, amidas e nitrato. É provável que o K, além de ativar redutase nitrato, também seja requerido para a síntese dessa enzima (Marschner, 1986).

Segundo Wallingford (1980), as principais funções do potássio na planta estão relacionadas à ativação enzimática, relações com a água, relações com energia, translocação de assimilados, captação de nitrogênio e síntese de proteínas e de amido.

As enzimas são necessárias em várias reações envolvidas na utilização de energia, síntese de amido, metabolismo do nitrogênio e respiração. O potássio é o único cátion monovalente disponível na natureza em quantidade suficiente, e com propriedades químicas apropriadas, para satisfazer a exigência da maioria das ativações enzimáticas por cátions monovalentes. A ativação enzimática pelo potássio ainda não está bem estabelecida, mas a teoria mais aceita é que o íon potássio hidratado combina com enzimas e altera sua conformação, facilitando a atividade das enzimas. Outra teoria é que o potássio atua como uma ponte entre a enzima e seu substrato, e, assim, as duas moléculas podem ser alinhadas apropriadamente para a reação (Wallingford, 1980).

Enzimas envolvidas nos processos de respiração como a piruvato quinase e na deterioração das sementes como as esterases, malato desidrogenase, álcool desidrogenase, catalase, peroxidase, dentre outras, têm um grande potencial como marcadores moleculares para monitorar e caracterizar a qualidade fisiológica de sementes, e se constituem em ferramentas de grande valor, pois, além de auxiliar no diagnóstico do estado físiológico de sementes, pode, em determinados casos, ajudar no entendimento sobre as causas da redução de vigor e viabilidade.

Neste trabalho, foi avaliado o efeito da adubação potássica e da calagem na composição química, qualidade fisiológica e na atividade enzimática de sementes de soja.

\section{MATERIAL E MÉTODOS}

A pesquisa foi desenvolvida nos laboratórios de análises e biotecnologia de sementes do Departamento de Agricultura e no laboratório do setor de produção vegetal do Departamento de Ciência dos Alimentos da Universidade Federal de Lavras (UFLA).

Foram utilizadas sementes do cultivar semiprecoce M-SOY 8001, semeadas com espaçamento de 0,5 m entre linhas, 15 plantas por metro. Cada parcela foi constituída de 6 linhas de 4 metros, sendo quatro consideradas como parcela útil. As adubações com cloreto de potássio $(\mathrm{KCl})$ foram realizadas nos sulcos no momento da semeadura, nas doses $\left(0 ; 50,100\right.$ e $\left.200 \mathrm{~kg} \cdot \mathrm{ha}^{-1} \mathrm{de}_{2} \mathrm{O}\right)$, sendo a dose de $100 \mathrm{~kg} \cdot \mathrm{ha}^{-1}$ de $\mathrm{K}_{2} \mathrm{O}$ parcelada em duas vezes e a dose de $200 \mathrm{~kg} \cdot \mathrm{ha}^{-1}$ de $\mathrm{K}_{2} \mathrm{O}$ parcelada em três vezes, e aplicadas de acordo com a fenologia da planta aos 25 dias (V2) e 35 dias (V4) após a semeadura. Foram utilizados dois níveis de saturação por base, um correspondendo ao nível observado por meio das análises de fertilidade na área de $48,6 \%$, e o segundo nível alcançado com a elevação da saturação por base para $85 \%$, utilizando-se o calcário dolomítico. A adubação básica foi realizada levando-se em consideração as características químicas do solo, sendo aplicados $120 \mathrm{~kg} \mathrm{ha}^{-1} \mathrm{de}_{2} \mathrm{P}_{5}$ e $2 \mathrm{~kg} \mathrm{ha}^{-1}$ de boro, utilizando Supersimples e Bórax. Os resultados de fertilidade, matéria orgânica e textura do solo, antes da aplicação dos tratamentos, foram: saturação por base de $48,3 \%$; $\mathrm{pH}$ em $\mathrm{H}_{2} \mathrm{O}$ de 5,$6 ; \mathrm{P}-1,2 \mathrm{mg} / \mathrm{dm}^{3} ; \mathrm{K}-79 \mathrm{mg} / \mathrm{dm}^{3} ; \mathrm{Ca}-1,6 \mathrm{cmol} /$ $\mathrm{dm}^{3} ; \mathrm{Mg}-1,4 \mathrm{cmol} / \mathrm{dm}^{3}$; matéria orgânica de $2,1 \mathrm{dag} / \mathrm{Kg}$ e teor de argila de $37 \%$.

Entre os estádios R7 e R8, as plantas foram colhidas manualmente, as vagens secadas, debulhadas e limpas manualmente, quando as sementes apresentavam em torno de $12 \%$ de teor de água, sendo este parâmetro medido, segundo metodologia proposta por Brasil (1992).

A avaliação da qualidade fisiológica foi realizada por meio dos testes de germinação e teste de envelhecimento acelerado.

Teste de germinação: foram utilizadas quatro repetições de 50 sementes por tratamento. A semeadura foi realizada em papel tipo Germitest $₫$, na forma de rolos e, posteriormente, mantidos no germinador à temperatura de $25^{\circ} \mathrm{C}$. A quantidade de água adicionada foi de 2,5 vezes o peso do papel seco, visando ao umedecimento adequado. As avaliações foram realizadas aos 7 dias após a semeadura, de acordo com os critérios estabelecidos nas Regras para Análise de Sementes (Brasil, 1992).

Teste de envelhecimento acelerado: foram seguidos os critérios estabelecidos por Marcos Filho (1999). Foram 
utilizadas amostras de sementes de $42 \mathrm{~g}$ por tratamento e colocadas sobre a tela de aço inoxidável adaptada em caixas plásticas "gerbox", contendo $40 \mathrm{ml}$ de água no seu interior. As caixas foram incubadas à temperatura de $41^{\circ} \mathrm{C}$ por 72 horas e a seguir foi realizado o teste de germinação, utilizando quatro repetições de 50 sementes por tratamento. A semeadura foi realizada em papel tipo Germitest e as sementes foram mantidas no germinador à temperatura de $25^{\circ} \mathrm{C}$. A quantidade de água adicionada foi de 2,5 vezes o peso do papel não hidratado. As contagens de plântulas normais foram feitas aos 4 e aos 7 dias após a semeadura.

Extrações de óleo e proteína: foram realizadas, segundo os métodos da Association of Official Agricultural Chemists (Association of Official Analytical ChemistsAOAC, 1995).

Atividade enzimática: após a eletroforese, procedeu-se à revelação das enzimas esterase, malato desidrogenase, álcool desidrogenase e piruvato quinase, segundo Alfenas \& Brune (1998).

Delineamento experimental: foram utilizados blocos ao acaso, em esquema de parcela subdivididas (2 níveis de saturação por bases $\mathrm{X} 4$ doses de potássio) com 4 repetições. Para as comparações entre as doses de potássio, foram realizadas análises de regressão e a análise dos dados foi realizada por meio do programa estatístico SISVAR (Ferreira, 2000).

\section{RESULTADOS E DISCUSSÃO}

A aplicação de doses crescentes de potássio e do calcário não influenciou a germinação de sementes de soja (Tabela 1). Resultados semelhantes foram encontrados por Tanaka et al. (1997), que trabalhando com diferentes doses de potássio, também não verificaram resposta positiva para a germinação de sementes de soja. Esses resultados contrariam aos observados por Mascarenhas et al. (1988), que descreveram o benefício do potássio sobre a germinação de sementes de soja.

Nos resultados de vigor de sementes, obtidos por meio do teste de envelhecimento acelerado, observou-se o efeito significativo da calagem na sobre o envigoramento das sementes, tanto na primeira (E14DAE) como na segunda leitura do teste (E2 - 7DAE). Maiores valores de vigor foram verificados nas sementes produzidas em área com saturação por base de $85 \%$, chegando a valores de $97 \%$ de vigor, após o envelhecimento das sementes. Essa diferença foi maior na avaliação realizada no quarto dia $\left(\mathrm{E}_{1}\right)$ após a semeadura (Tabela 2).

Esse vigor na fase inicial do processo de germinação é fundamental para o estabelecimento de plantas no campo, principalmente sob condições de estresse, após a semeadura. Resultados significativos do efeito da calagem no vigor de sementes também foram observados por Turkiewicz (1976), citado por Sá \& Buzetti (1994).

Foram observados aumentos nos teores de óleo com o aumento nas doses de $\mathrm{K}_{2} \mathrm{O}$ utilizadas, independentemente da saturação por base. Valor de teor de óleo acima de $19 \%$ foi verificado para a aplicação de 200 kg. ha ${ }^{-1}$ de $\mathrm{K}_{2} \mathrm{O}$ (Figura 1).

Tabela 1 - Resumo da análise de variância dos resultados das avaliações para teores de óleo e de proteína, germinação (G\%) e envelhecimento acelerado (E1 e E2) de sementes, cultivar M-SOY 8001 submetidas aos tratamentos com e sem calagem e diferentes doses de potássio. UFLA, Lavras, MG, 2007.

\begin{tabular}{lcccccc}
\hline \multirow{2}{*}{ Fontes de variação } & \multicolumn{5}{c}{ Quadrados médios } \\
\cline { 2 - 7 } & GL & G $(\%)$ & E1 $(\%)$ & E2 $(\%)$ & Óleo & Proteína \\
\hline Blocos & 3 & 11,50 & 1,13 & 3,12 & 0,13 & 0,42 \\
Calagem & 1 & 2,00 & $136,13^{*}$ & $105,12^{*}$ & 0,25 & $5,02^{*}$ \\
Erro 1 & 3 & 0,33 & 7,46 & 5,46 & 0,71 & 1,03 \\
Potássio & 3 & 2,83 & 65,46 & 17,12 & $1,92^{*}$ & $6,1 *$ \\
C x P & 3 & 1,67 & 39,12 & 20,12 & 0,38 & 0,98 \\
Erro 2 & 18 & 2,25 & 17,18 & 10,18 & 0,45 & 1,11 \\
Total & 31 & & & & 4,5 & 2,66 \\
CV 1 & & 0,60 & 3,05 & 2,47 & 3,58 & 2,76 \\
CV 2 & 1,57 & 4,62 & 3,37 & & \\
\hline
\end{tabular}

\footnotetext{
* significativo, a $5 \%$ de probabilidade.
} 
Tabela 2 - Valores de vigor após o envelhecimento acelerado das sementes, em função do uso da calagem. UFLA, Lavras, MG, 2007.

\begin{tabular}{ccc}
\hline Calagem & E1 $(\%)$ & E2(\%) \\
\hline Com & $97 \mathrm{a}$ & $97 \mathrm{a}$ \\
Sem & $82 \mathrm{~b}$ & $92 \mathrm{~b}$
\end{tabular}

As médias seguidas de letras minúsculas distintas na coluna diferem entre si pelo teste de Tukey, a 5\% de probabilidade.

Os resultados observados nessa pesquisa corroboram com os observados por outros autores. De acordo com Mascarenhas et al. (1988), o potássio é essencial na síntese e no transporte de óleo para os grãos. Também, segundo Usherwood (1994), o potássio tem função no transporte de fotoassimilados para os grãos, permitindo a síntese de óleo. Em sementes, o potássio exerce efeito positivo sobre o teor de óleo (Tanaka et al., 1997), porém, estes não estão de acordo com os verificados por Kanthack (1995) que, trabalhando em um latossolo vermelho, textura arenosa, não encontrou efeito significativo de doses e modos de aplicação do K sobre a produção de óleo em sementes de soja.

Observou-se, pela Figura 2, que houve redução nos teores de proteína na medida em que as doses de potássio foram aumentadas, atingindo teor mínimo de proteína na dose $160 \mathrm{~kg}$. ha-1 de $\mathrm{K}_{2} \mathrm{O}$. Tanaka et al. (1995) verificaram que aumentou-se o teor de proteína e diminui o teor de óleo, com o aumento de $\mathrm{K}_{2} \mathrm{O}$ no solo.

Em sementes produzidas com a aplicação da calagem e consequente elevação da saturação por base a $85 \%$ foram observados maiores teores de proteínas em relação aos verificados em sementes produzidas em solo com $48 \%$ de saturação por base (Tabela 3 ).

Segundo Mascarenhas et al. (1996), a calagem proporciona melhores condições para a fixação biológica do nitrogênio atmosférico, em razão de alterações no pH do solo e também maior disponibilidade de molibdênio.

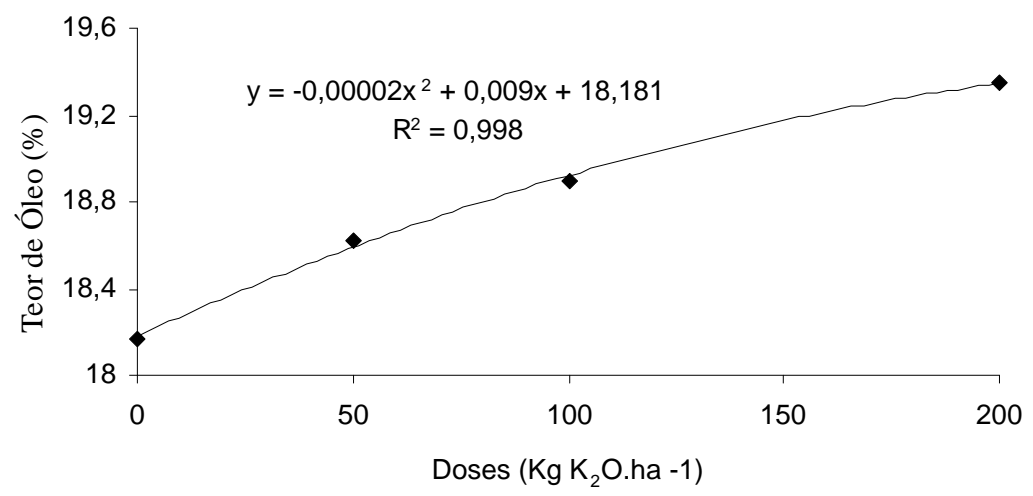

Figura 1 - Representação gráfica da equação de regressão para os resultados dos teores de óleo, em função das doses de potássio aplicadas no solo. UFLA, Lavras, MG, 2007.

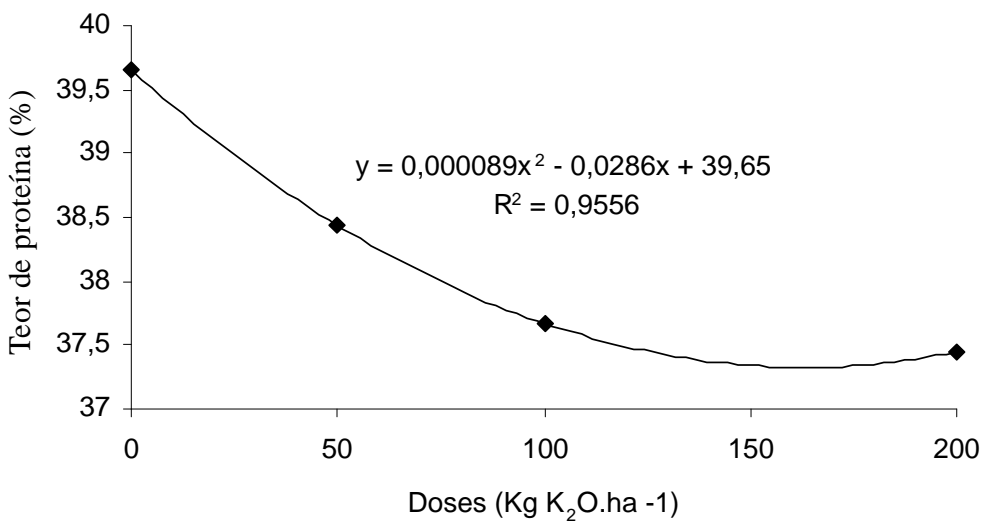

Figura 2 - Representação gráfica da equação de regressão para os teores de proteína em função das doses de potássio aplicadas no solo. UFLA, Lavras, MG, 2007. 
Dessa forma, sendo molibdênio um dos componentes da enzima redutase de nitrato, a sua presença em maior teor proporciona a formação de mais aminoácidos, portanto, de proteína, independente da dose de potássio aplicada.

Em trabalho realizado por Souza et al. (2009), não foram verificados efeitos significativos na composição química foliar e nos teores de proteína e óleo nos grãos de soja, em função da aplicação de micronutrientes.

Tabela 3 - Valores de teor de proteína em função do uso da calagem. UFLA, Lavras, MG, 2007.

\begin{tabular}{lc}
\hline Calagem & Teor de proteína $(\%)$ \\
\hline Com & $39,05 \mathrm{a}$ \\
Sem & $37,56 \mathrm{~b}$ \\
\hline
\end{tabular}

As médias seguidas de letras minúsculas distintas na coluna diferem entre si pelo teste de Tukey, a 5\% de probabilidade.

Pela avaliação do sistema enzimático revelado para a enzima piruvato quinase, foi observada maior atividade em sementes produzidas com $100 \mathrm{~kg} \cdot \mathrm{ha}^{-1}$ e $200 \mathrm{~kg} \mathrm{ha}^{-1} \mathrm{de}$ $\mathrm{K}_{2} 0$ e saturação por base de $85 \%$ (Figura 3).

Pode ser observado que, a piruvato quinase, a qual converte o fosfoenolpiruvato em piruvato com liberação de ATP, em uma etapa final da via glicolítica, apresenta alto requerimento de potássio. As concentrações ideais de potássio são necessárias para induzir as variações conformacionais e a otimização do grau de hidratação da enzima e, portanto, máxima ativação. Em geral, a mudança conformacional das enzimas induzidas pelo $\mathrm{K}^{+}$, aumenta a taxa de atividade, velocidade máxima de absorção e, em alguns casos, também à afinidade para com o substrato Km (Faquin, 2005). A glicólise é uma das etapas da respiração, importante nas fases iniciais da germinação de sementes, assim, torna-se importante avaliar enzimas que são ativadas nas fases iniciais da respiração, como, por exemplo, da glicólise.

Para o sistema enzimático álcool desidrogenase (ADH), foi observada uma maior atividade em sementes produzidas com o uso calagem quando comparativamente àquelas produzidas sem a elevação da saturação por base. Essa ocorrência sugere a presença de respiração anaeróbica (Figura 4).

A enzima álcool desidrogenase (ADH) reduz acetaldeído para etanol no metabolismo anaeróbico. Quando a atividade dessa enzima diminui, a semente fica mais susceptível à ação deletéria do acetaldeído (Zhang et al., 1994), que é mais tóxico para as células que o etanol formado na presença da enzima $\mathrm{ADH}$.

Para o sistema enzimático malato desidrogenase (MDH), não foram observadas diferenças entre os padrões eletroforéticos das sementes submetidas aos diferentes tratamentos (Figura 5).

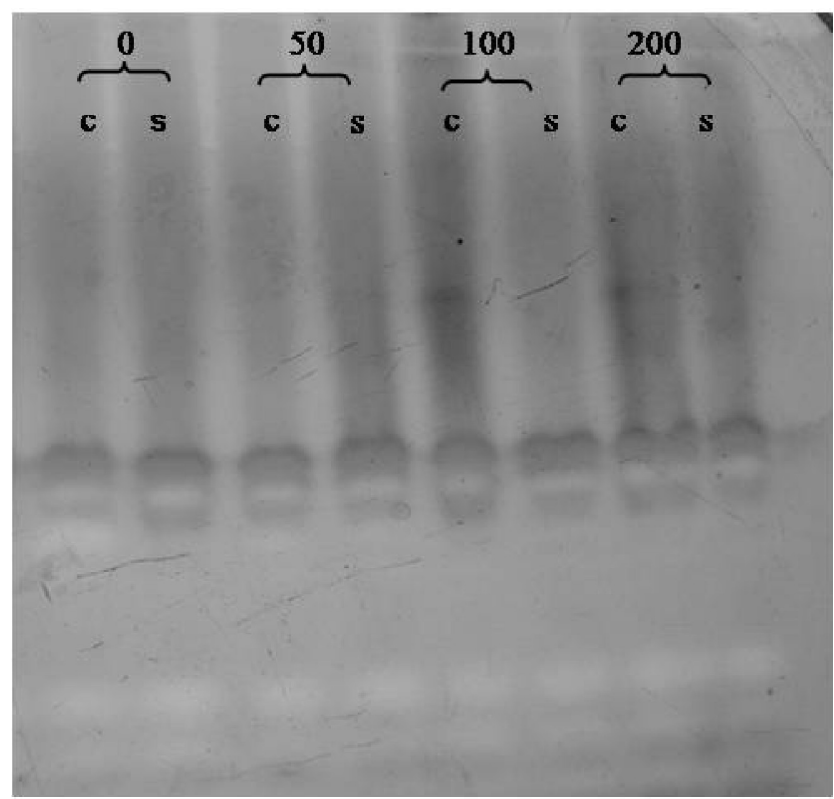

Figura 3 - Padrões enzimáticos de sementes de soja com e sem o uso de calagem (c,s) e doses de potássio $(0,50,100$ e $200 \mathrm{~kg} \cdot$ ha $^{-1}$ ), revelados para piruvato quinase. UFLA, Lavras, MG, 2007. 
Embora não tenha sido observada inluência da adubação com potássio e da calagem na atividade da MDH, esta é uma enzima bastante utilizada para acompanhamento da qualidade de sementes, por se tratar de uma enzima envolvida na respiração celular que transforma malato em oxaloacetato, produzindo um NADH, o qual é utilizado para gerar energia. A atividade desta enzima está relacionada à exposição de organismos aos diferentes estresses, como por exemplo, o envelhecimento acelerado de sementes, que simula o amarzenamento (Camargo et al., 2000).

Em relação aos padrões observados para a enzima esterase, maiores atividade dessa enzima foram observadas em sementes produzidas com saturação por base de $85 \%$, com calagem, associada à aplicação de $\mathrm{K}_{2} \mathrm{O}$ nas doses de 50 e $100 \mathrm{~kg} \mathrm{ha}^{-1}$ (Figura 6).

Essa enzima pode estar envolvida no desdobramento de lipídeos, durante o processo de germinação das sementes. Esse processo é importante para a retomada do crescimento do eixo embrionário, principalmente em sementes ricas em lipídeos, como é o caso da soja. Na presente pesquisa, foi observado aumento no teor de óleo nas sementes, com o aumento das doses de K. No entanto, em sementes produzidas sob as doses de 0 e $200 \mathrm{~kg}$ não foram observadas diferenças nos padrões da enzima esterase.

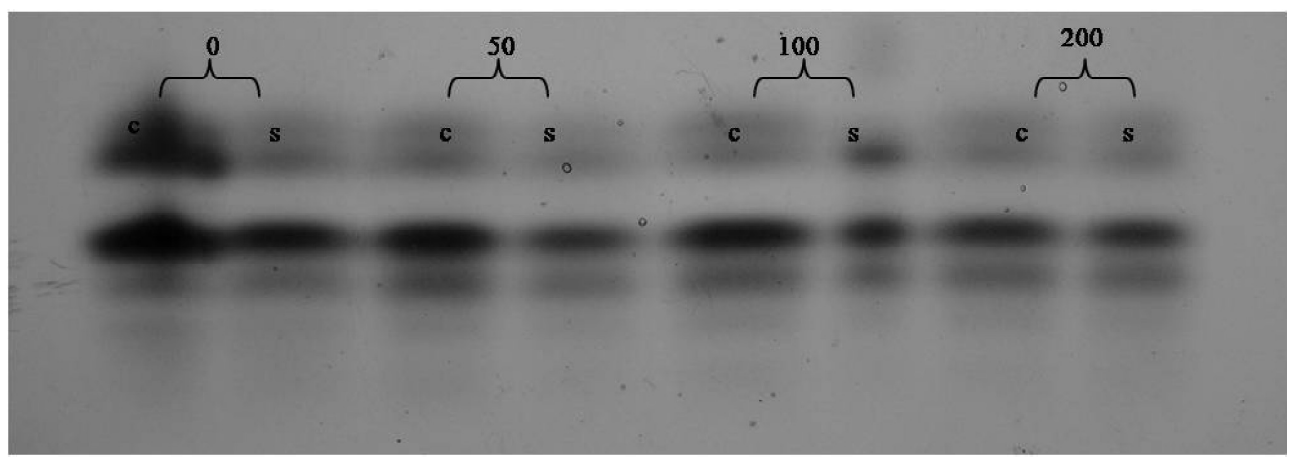

Figura 4 - Padrões enzimáticos de sementes de soja com e sem o uso da calagem (c,s) e doses de potássio $(0,50,100$ e $200 \mathrm{~kg} \cdot \mathrm{ha}^{-1}$ ), revelados para álcool desidrogenase (ADH) UFLA, Lavras, MG, 2007.

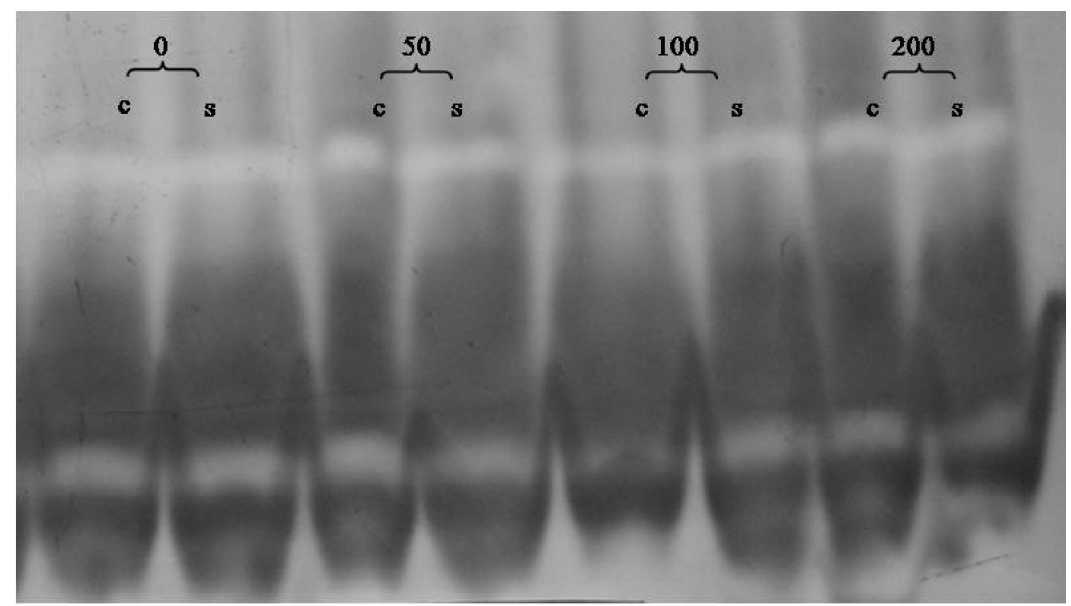

Figura 5 - Padrões enzimáticos de sementes de soja com e sem o uso da calagem (c, s) e doses de potássio $(0,50,100$ e $200 \mathrm{~kg} \cdot$ ha $^{-1}$ ), revelados para malato desidrogenase (MDH) UFLA, Lavras, MG, 2007. 


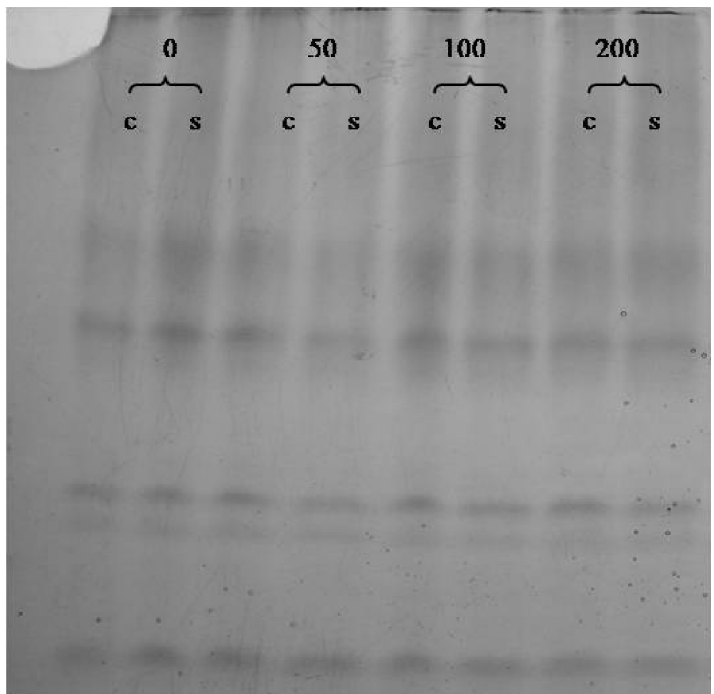

Figura 6 - Padrões enzimáticos de sementes de soja com e sem o uso da calagem (c, s) e doses de potássio $(0,50$, 100 e $200 \mathrm{~kg} . \mathrm{ha}^{-1}$ ), revelados para esterase (EST), UFLA, Lavras, MG, 2007.

\section{CONCLUSÕES}

A adubação potássica não afeta a germinação e o vigor das sementes.

Aumento na saturação por base proporciona maior vigor de sementes de soja.

À medida que aumenta a dose $\mathrm{K}_{2} \mathrm{O}$ aumenta o teor de óleo e reduz o teor de proteína em sementes de soja .

Aumenta o teor de proteínas em sementes de soja produzidas sob maiores níveis de saturação por base.

A atividade das enzimas piruvato quinase, esterase e álcool desidrogenase em sementes de soja é afetada pela concentração de potássio e saturação por base no solo.

\section{REFERÊNCIAS BIBLIOGRÁFICAS}

ALFENAS, A.C.; BRUNE, W. Eletroforese em gel de poliacrilamida. In: ALFENAS, A.C. Eletroforese de isoenzimas e proteínas afins: fundamentos e aplicações em plantas e microrganismos. Viçosa, MG: UFV, 1998. p.151-182.

\section{ASSOCIATION OF OFFICIAL ANALYTICAL CHEMISTS. Official methods of analysis. 16.ed. Arlington, 1995. 190p.}

BRASIL. Ministério da Agricultura e Reforma Agrária. Secretaria Nacional de Defesa Agropecuária. Regras para análise de sementes. Brasília, 1992. 365p.

BRIM, C.A. Quantitative genetics and breeding. In: CALDWELL, B.E.; HOWELL, R.W.; JOHNSON, H.W.
(Ed.). Soybeans: improvement, production and uses. Madison: American Society of Agronomy, 1973. p.172.

CAMARGO, M.L.P.; MORI, E.S.; MELLO, E.J.; ODA, S.; LIMA, P. Atividade enzimática em plântulas de Eucalyptus grandis provenientes de sementes envelhecidas artificialmente e naturalmente. Ciência Florestal, Santa Maria, v.10, n.2, p.113-122, 2000.

FAQUIN, V. Nutrição mineral de plantas. Lavras: UFLA/ FAEPE, 2005. 183p.

FERREIRA, D.F. Análises estatísticas por meio do Sisvar para Windows versão 4.0. In: REUNIÃO ANUAL DA REGIÃO BRASILEIRA DA SOCIEDADE

INTERNACIONAL DE BIOMETRIA, 45., 2000, São

Carlos. Anais... São Carlos: UFSCAR, 2000. p.255-258.

KANTHACK, R.A.D. Efeito de doses e modo de aplicação de potássio em características agronômicas de soja. 1995. 118p. Dissertação (Mestrado em Fitotecnia)-Escola Superior de Agricultura Luiz de Queiroz, Piracicaba.

MARCOS FILHO, J. Teste de envelhecimento acelerado. In: FRANÇA NETO, J.B.; VIEIRA, R.D.; KRZYZANOWSKI, F.C. (Ed.). Vigor de sementes: conceitos e testes. Londrina: ABRATES, 1999. 
MARSCHNER, H. Mineral nutrition of higher plants. London: Academic, 1986. 390p.

MASCARENHAS, H.A.A.; BULISANI, E.A.; MIRANDA, M.A.C.; PEREIRA, J.C.V.N.A.; BRAGA, N.R. Deficiência de potássio em soja no estado de São Paulo: melhor entendimento do problema e possíveis soluções. Informações Agronômicas, Piracicaba, n.42, p.1-4, jun. 1988 .

MASCARENHAS, H.A.A.; TANAKA, R.T.; GALLO, P.B.; PEREIRA, J.C.V.N.A.; AMBROSANO, G.M.B.; CARMELO, Q.A.C. Efeito da calagem sobre produtividade de grãos, óleo, proteína em cultivares precoces de soja. Scientia Agricola, Piracicaba, v.53, n.1, jan./abr. 1996.

MASCARENHAS, H.A.A.; TEIXEIRA, J.P.F.; NAGAI, V.; TANAKA, R.T.; GALLO, P.B.; PEREIRA, J.C.V.N.A; MIRANDA, M.A.C. Rates of liming on the concentration and yield of oil and protein in soybeans. In: INTERNATIONAL MEETING ON FATS, OILS AND TECNOLOGY, 1991, Campinas. Proceedings... Campinas: Unicamp, 1991. p.157-161.

SÁ, M.E.; BUZETTI, S. Importância da adubação na qualidade dos produtos agrícolas. São Paulo: Ícone, 1994. 437p.

SEDIYAMA, C.S.; VIEIRA, C.; SEDIYAMA, T.; CARDOSO, A.A.; ESTEVÃO, H.H. Influência do retardamento da colheita sobre a deiscência das vagens e sobre a qualidade e poder germinativo das sementes de soja. Experientiae, Viçosa, v.14, n.5, p.117-141, 1972.
SOUZA, L. C. F. de; ZANON, G. D.; PEDROSO, F. F.; ANDRADE, L. H. L. de. Teor de proteína e de óleo nos grãos de soja em função do tratamento de sementes e aplicação de micronutrientes. Ciência e Agrotecnologia, Lavras, v. 33, n. 6, p. 1586-1593, nov./dez., 2009.

TANAKA, R.T.; MASCARENHAS, H.A.A; ARCE, M.A.R. d'; GALLO, P.B. Concentração e produtividade de óleo e proteína de soja em função da adubação potássica e da calagem. Pesquisa Agropecuária Brasileira, Brasília, v.30, n.4, p.463-9, abr. 1995.

TANAKA, R.T.; MASCARENHAS, H.A.A.; MIRANDA, M.A.C. Effect of liming on soybean protein and oil yield. Better Crops International, Atlanta, v.7, n.2, p.9, 1991.

TANAKA, R.T.; MASCARENHAS, H.A.A.; MURUOKA, T.; GALLO, P.B. Changes in soybean quality resulting from applications of lime and potassium fertilizer. Plant Nutrition, Monticello, p.943-944. 1997.

USHERWOOD, N.R. Potassium interactions and balanced plant nutrition. Better Crops With Food, Atlanta, v.77, n.1, p.26-27, 1994.

WALLINGFORD, W. Functions of potassium in plant. In:__. Potassium for agriculture. Atlanta: Potash \& Phosphate Institute, 1980. p.10-27.

ZHANG, M.; MAEDA, Y.; FUTIHATA, Y.; NORRAMURA, Y.I.; ESASHI, Y. A mechanism of seed deterioration in relation to volatile compounds evoked by dry seeds themselves. Seed Science Research, Wellingford, v.4, n.1, p.49-56, Mar. 1994. 